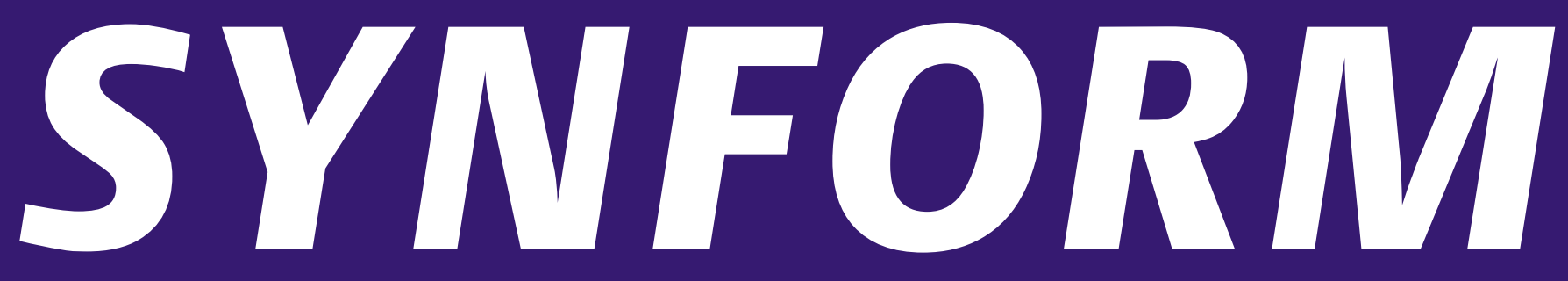

People, Trends and Views in Synthetic Organic Chemistry

Asymmetric Autocatalysis Triggered by Carbon Isotope $\left({ }^{13} \mathrm{C} /{ }^{12} \mathrm{C}\right)$ Chirality

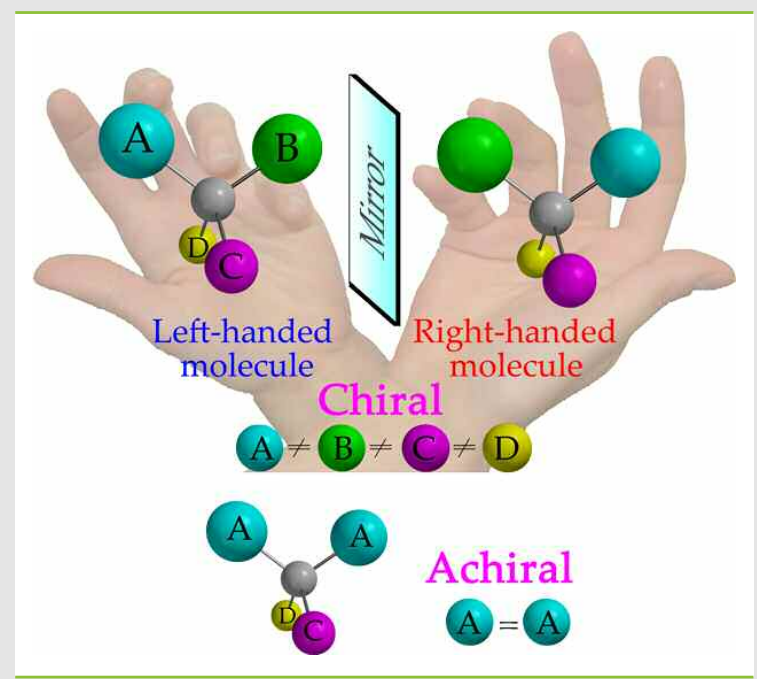

Orthogonal Synthesis of Isoindoles and Isoquinolines via 1,3-Dipolar Cycloaddition and Electrocyclization
Thieme-Chemistry Journals

Editorial Board Meetings 2009
Your opinion about SYNFORM is welcome, please correspond if you like: marketing@thieme-chemistry.com 


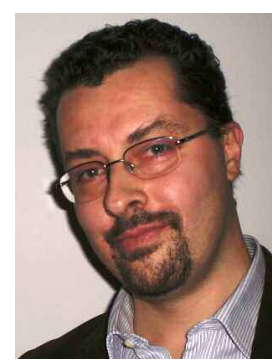

\section{Dear readers,}

I am writing this brief editorial while spending my holidays in Sardinia.

Right now, I am on a terrace with a wonderful view of the sea, blue sky, a delightful breeze and an ice-cold cocktail.

But SYNFORM can't wait; therefore, my laptop had to come out from the bag where it spent one entire week of unusual rest.

But I am sure it's a worth deal, because also in this issue SYNFORM features very interesting science. In the first SYNSTORY Professor Chiba from Singapore discloses new information about his novel approach to isoindoles and isoquinolines, whereas in another SYNSTORY Professor Soai from Japan explains how he and his co-workers were able to publish the first example of stereoselectivity controlled by stereogenic centers bearing ${ }^{12} \mathrm{C}$ or ${ }^{13} \mathrm{C}$ carbon isotopes. The issue is closed by a brief report on the Thieme-Chemistry Journals Editorial Board Meetings recently held in Granada (Spain).

Enjoy your reading!!!

Matteo Zanda

Editor of SYNFORM

\section{IN THIS ISSUE}

\section{SYNSTORIES}

Orthogonal Synthesis of Isoindoles and Isoquinolines via 1,3-Dipolar Cycloaddition and Electrocyclization.

Asymmetric Autocatalysis Triggered by

Carbon Isotope $\left({ }^{13} \mathrm{C} /{ }^{12} \mathrm{C}\right)$ Chirality A54

Thieme-Chemistry Journals Editorial Board Meetings 2009 A57

COMING SOON A58

If you have any questions or wish to send feedback, please write to Matteo Zanda at: synform@chem.polimi.it 


\title{
Orthogonal Synthesis of Isoindoles and Isoquinolines via 1,3-Dipolar Cycloaddition and Electrocyclization
}

\author{
Org. Lett. 2009, 11, 729-732; Synfacts 2009, 479 (Synfact of the Month)
}

Nitrogen-containing heterocycles (azaheterocycles) are important and widespread structures, present in numerous natural products, potent pharmaceutical drugs, and various kinds of functional materials. Although a number of diverse synthetic approaches toward azaheterocycles have been developed it is still highly desirable to exploit versatile methodologies to construct such molecules with selective control of substitution patterns using readily accessible building blocks. The group of Professor Shunsuke Chiba from the Nanyang Technological University in Singapore has recently been interested in the chemical reactivity of organic azides to synthesize azaheterocycles via various types of $\mathrm{C}-\mathrm{N}$ bond formations.

"During the course of our studies," explained Professor Chiba, " $\alpha$-azido carbonyl compounds containing a 2-alkenylaryl unit were found to be promising precursors for the synthesis of isoindole and isoquinoline derivatives via 1,3-dipolar cycloaddition of azides onto alkenes and $6 \pi$-electrocyclization of $N-\mathrm{H}$ imine intermediates, respectively." According to Professor Chiba, this methodology exploits orthogonal modes of chemical reactivity of such organic azides, displayed by slight modification of the reaction conditions as shown in the scheme below.
Isoindoles could be accessed by simple heating of the starting organic azides in toluene, whereupon intramolecular azido-alkene cycloaddition and consecutive elimination of dinitrogen from the resulting triazolines would produce isoindoles. "The appeal of isoindoles prepared by this methodology can be attributed to not only their attractive fluorescent and electroluminescent properties but also their versatility as reaction precursors for the synthesis of oligoacenes," said Professor Chiba. "By using newly synthesized isoindoles, we are now aiming to prepare new types of oligoacenes with a range of substituents."

Chiba and Hui discovered the second reactivity pattern of these organic azides - to provide isoquinoline derivatives serendipitously, when direct conversion of the mesylate into the isoindole was tried using 1.5 equivalents of $\mathrm{NaN}_{3}$ in $\mathrm{DMF}$ at $100{ }^{\circ} \mathrm{C}$ via a substitution reaction followed by an azidoalkene 1,3-dipolar cycloaddition (for details, see the original paper). "After understanding that the excess amount of $\mathrm{NaN}_{3}$ induced the formation of $\mathrm{N}-\mathrm{H}$ imine," he concluded, "we soon elucidated the optimized reaction conditions to provide isoquinolines selectively."<smiles>CCOC(=O)C(C)c1ccccc1C=C(C)C</smiles>

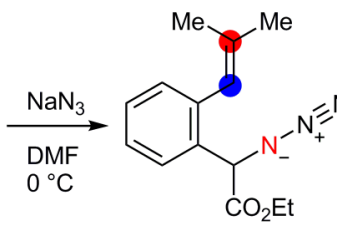<smiles>CCOC(=O)C1c2ccccc2OC(I)N1Cc1ccccc1</smiles>

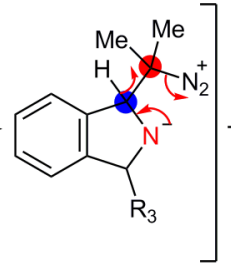<smiles></smiles><smiles>CCOC(C)c1ccccc1C=C(C)C</smiles>

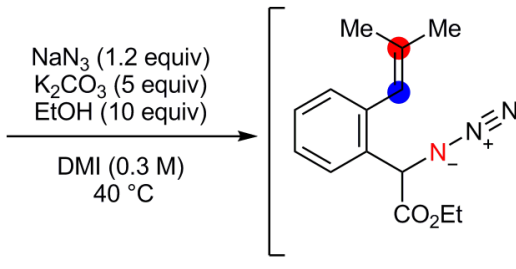<smiles>c1ccc2ncccc2c1</smiles><smiles>CCOC(=O)c1ccccc1OC(C)=O</smiles><smiles>CCOC(=O)c1nc(C)nc2ccc(C(C)(C)C)cc12</smiles> 


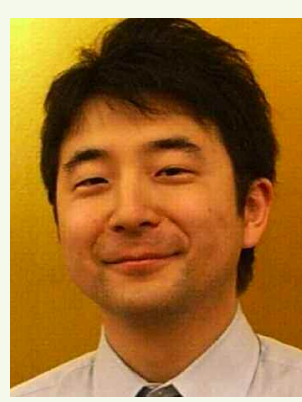

Prof. S. Chiba
Shunsuke Chiba was born in Kanagawa (Japan) in 1978. He obtained his B.Eng. degree from Waseda University (Japan) in 2001 and received his Ph.D. degree in 2006 from the University of Tokyo (Japan), the latter under the supervision of Professor Koichi Narasaka. He was appointed as a Research Associate in Professor Narasaka's group at the University of Tokyo in 2005. In 2007, he moved to the

Division of Chemistry \& Biological Chemistry, School of

Physical \& Mathematical Sciences, Nanyang Technological University (Singapore) as an Assistant Professor. His research is focused on the development of organic synthetic methodologies and the synthesis of natural and unnatural products.

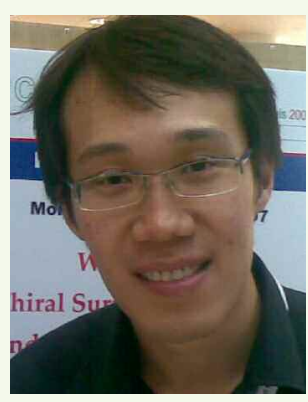

Benjamin Wei-Qiang Hui was born in Singapore in 1982 and obtained his bachelor's degree in chemistry from the National University of Singapore (NUS) in 2007. In the same year, he entered the graduate program at Nanyang Technological University (NTU) under the supervision of Professor Shunsuke Chiba. His research focuses on the development of new synthetic methods to access azaheterocyclic compounds.

\section{INFORMATION + + + +}

\section{Synthesis Reviews}

Your free database of review articles in synthetic organic chemistry!

- Contains 24860 review articles (from journals and books)

- Covers literature from 1970 to the end of 2008 and is updated annually

- Is hosted by SYNTHESIS \& SYNLETT

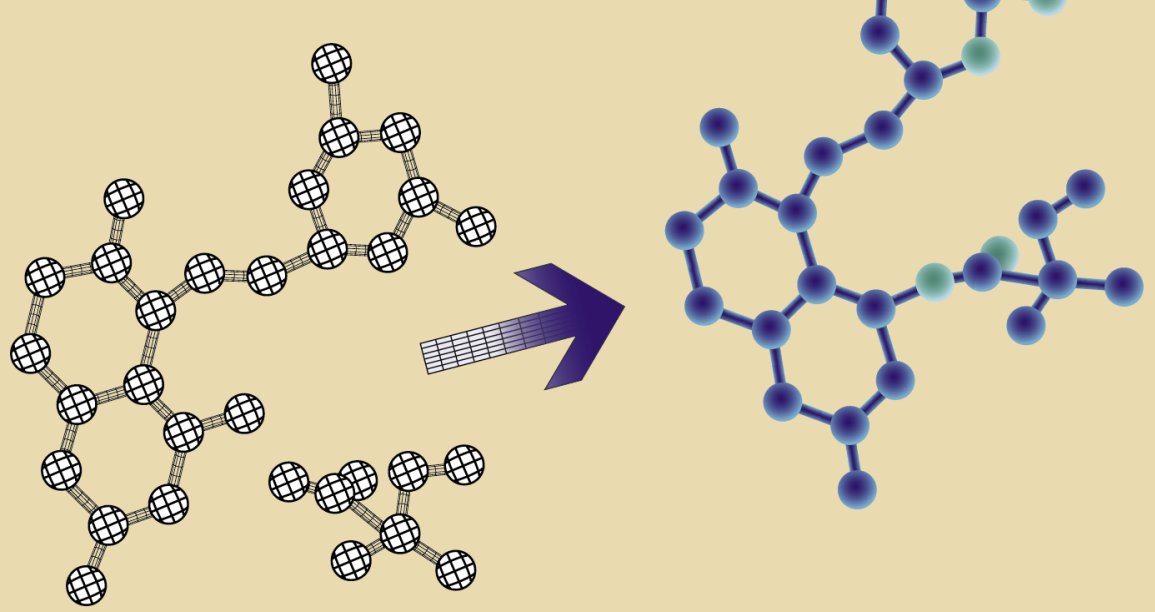




\title{
Asymmetric Autocatalysis Triggered by Carbon Isotope $\left({ }^{13} \mathrm{C} /{ }^{12} \mathrm{C}\right)$ Chirality
}

\author{
Science 2009, 324, 492-495
}

The origin of homochirality of biomolecules such as Lamino acids and D-sugars has attracted significant interest of many researchers. Many apparently achiral molecules may be chiral because of random substitution of the $1.1 \%$ naturally abundant ${ }^{13} \mathrm{C}$ for ${ }^{12} \mathrm{C}$. ${ }^{1}$ Hydrogen isotope chirality (H/D) in a polymer has been shown to cooperatively control macromolecular helical handedness. ${ }^{2}$

However, because the effect of carbon isotopic chirality is far smaller than hydrogen isotopic chirality, it has been a question whether carbon-isotopically chiral compounds can per- form asymmetric induction in organic reactions. A brilliant answer to this intriguing question came recently from Professor Kenso Soai and his group from the Tokyo University of Science (Japan), who demonstrated that carbon isotope chirality can actually trigger asymmetric autocatalysis, at least in appropriately designed systems.

"We have been studying asymmetric autocatalysis reactions in which a chiral product acts as a chiral catalyst for its own production," said Professor Soai. "Our asymmetric autocatalysis of pyrimidyl alkanol in the reaction between pyrimi-

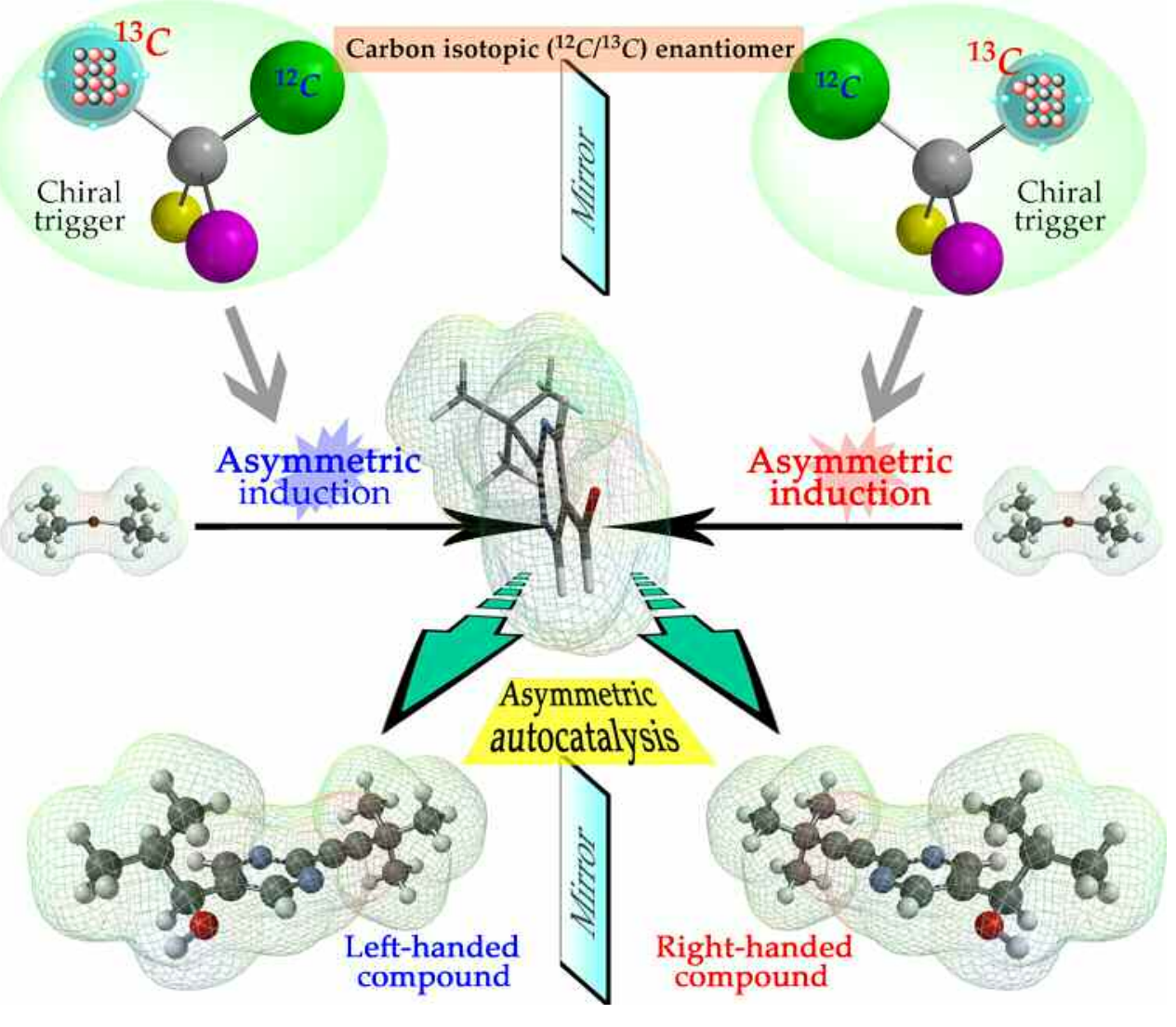




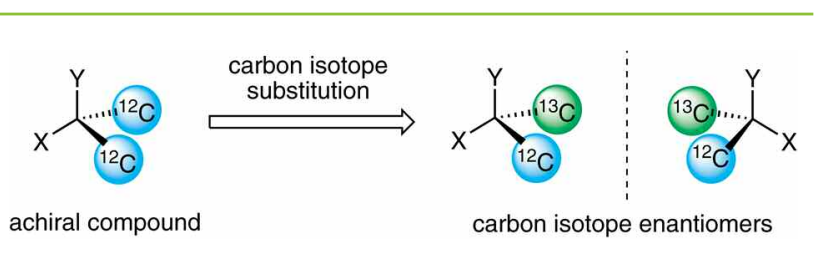

dine-5-carbaldehyde and diisopropylzinc exhibits significant amplification of chirality, that is, starting from an asymmetric autocatalyst with extremely low enantiomeric excess (ee), three consecutive asymmetric autocatalyses afford almost enantiopure ( $>99.5 \%$ ee) pyrimidyl alkanol with significant multiplication of the amount. ${ }^{3}$ Moreover," he continued, "when the asymmetric autocatalysis is initiated in the presence of a chiral initiator with tiny enantiomeric imbalance, the highly enantioenriched product with the absolute configuration correlated with that of the chiral initiator is formed. So far, we have used cryptochiral compounds, including a saturated quaternary hydrocarbon, as chiral initiators."

The use of such compounds - chiral only because of the carbon isotope chirality - as the chiral initiators of asymmetric autocatalysis was a challenge for the Soai group because of the small difference in atomic weight (only 8\%) between ${ }^{13} \mathrm{C}$ and ${ }^{12} \mathrm{C}$. "To the best of our knowledge," confirmed Professor Soai, "there has been no report on asymmetric induction using carbon isotope chirality." In the course of the research, Professor Soai and his coworkers paid the utmost attention to exclude the effect of chiral materials other than those featuring the ${ }^{13} \mathrm{C} /{ }^{12} \mathrm{C}$ isotope chirality. "For example," said Professor Soai, "we prepared both enantiomers of dimethylphenylmethanol ${ }^{13} \mathrm{C} /{ }^{12} \mathrm{C}$ isotopes by independent methods. By using the same enantiomer of chiral catalyst, the enantioselective additions of (A) ${ }^{13} \mathrm{C}$-labelled dimethylzinc $\left[\left({ }^{13} \mathrm{CH}_{3}\right)_{2} \mathrm{Zn}\right]$ to acetophenone and (B) $\left(\mathrm{CH}_{3}\right)_{2} \mathrm{Zn}$ to ${ }^{13} \mathrm{C}$-labelled acetophenone $\left(\mathrm{C}_{6} \mathrm{H}_{5} \mathrm{CO}^{13} \mathrm{CH}_{3}\right)$ gave the opposite enantiomers of which one of the methyl groups is ${ }^{13} \mathrm{C}$-labelled. Thus," continued Professor Soai, "even if any contaminant derived from the chiral catalyst were present in the enantiomeric dimethylphenylmethanol, it would have the same chirality and would effect the reaction in the same sense of chirality." The experimental results clearly revealed that, as anticipated by the authors, the absolute configuration of the carbon-isotopically chiral compound controlled the absolute configuration of the product; that is, ${ }^{13} \mathrm{C} /{ }^{12} \mathrm{C}$ chirality induced an enantioenrichment in the asymmetric reaction.

"Because the asymmetric autocatalysis has now been shown to be capable of discriminating the ${ }^{13} \mathrm{C} /{ }^{12} \mathrm{C}$ chirality," concluded Professor Soai, "the concept of the origin of chirality may have expanded significantly."

In a comment on this work, Professor Guy C. Lloyd-Jones from the University of Bristol (UK) and Editorial Advisory Board member of the Thieme-Chemistry journals, said: "This is a beguiling piece of work: elegant in design and packed full

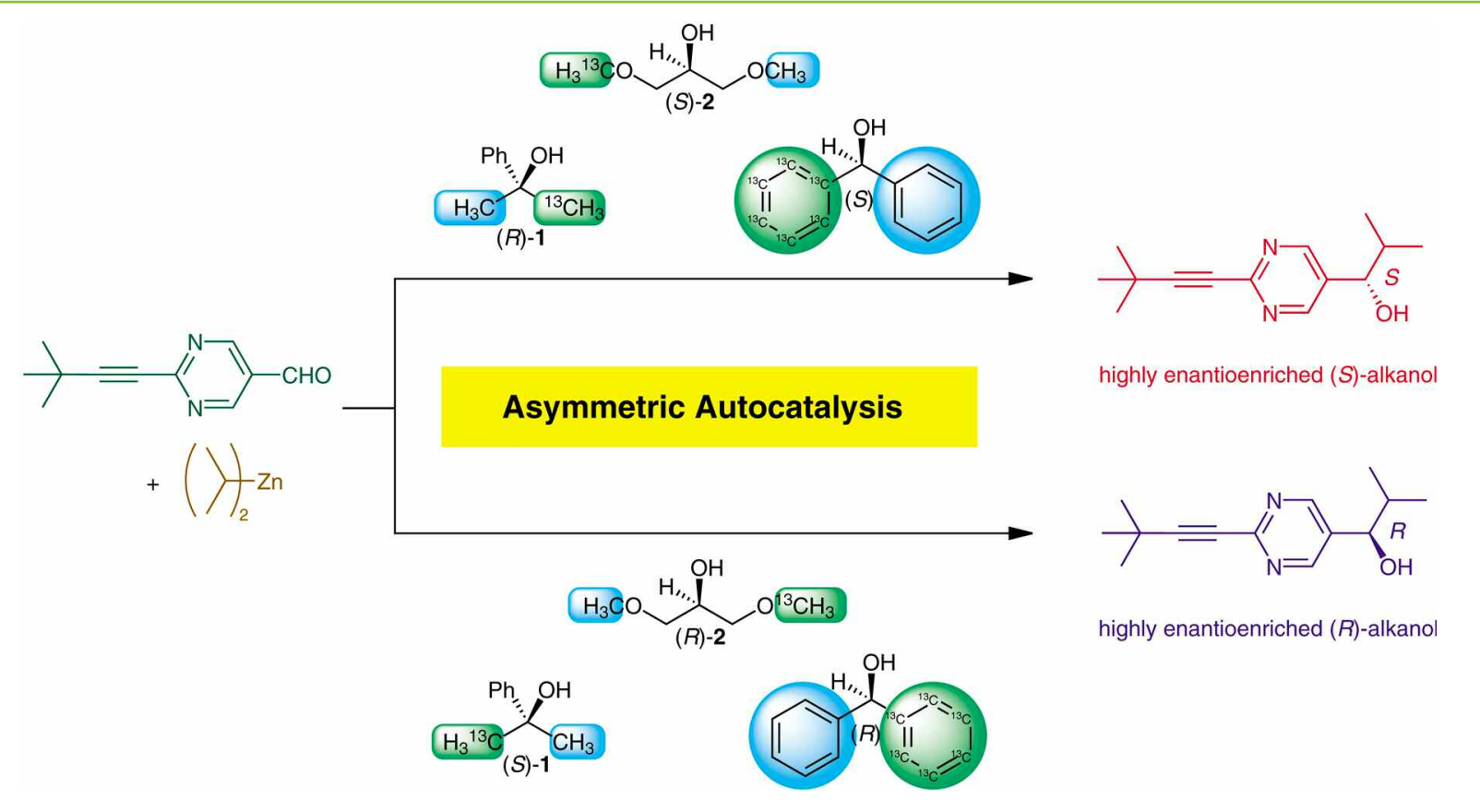


of painstaking experimentation. A heavy-isotope effect (of asyet undetermined mechanism) in highly enantioenriched alcohols that are chiral solely by virtue of ${ }^{13} \mathrm{C}$ incorporation is able to exert sufficient influence on the early stages of Soai's highly tuned $i-\mathrm{Pr}_{2} \mathrm{Zn}$ /pyrimidine aldehyde reaction to trigger asymmetric autocatalysis. There is a highly reproducible sense of enantiomer induction, and the control experiments, for example using the same enantiomer of ligand to make both enantiomers of alcohol $\mathbf{1}$, and the stereoinversion to synthesize the enantiomer of alcohol $\mathbf{2}$, are impressive. One is left with the feeling that the effect is genuine and significant. Soai reports on a challenging, erudite and fascinating study that will undoubtedly stimulate the search for other manifestations of this subtle chirality," concluded Professor Lloyd-Jones.

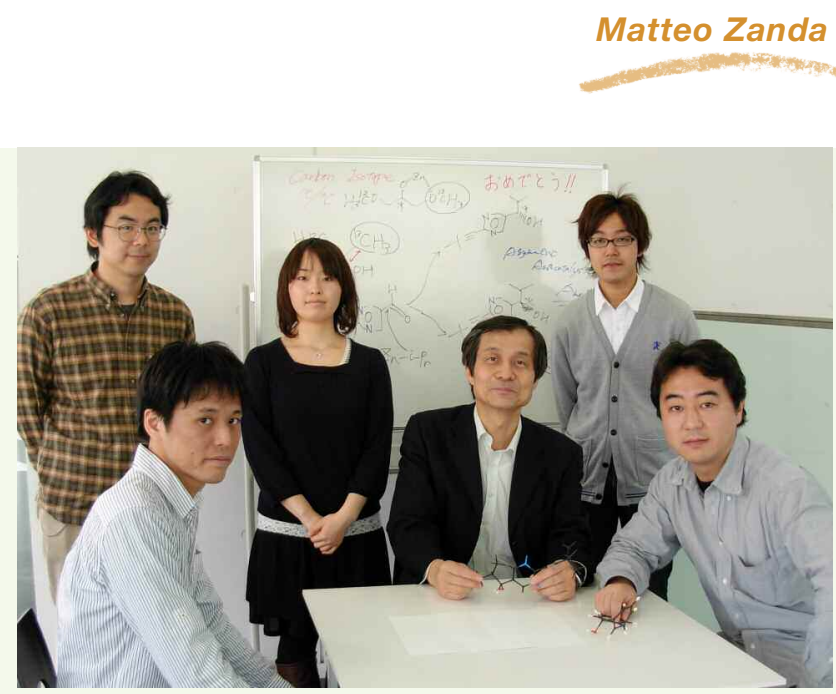

From left to right: K. Suzuki, T. Tsutsumi, Y. Matsumura, Prof. K. Soai, M. Ito, Dr. T. Kawasaki

\section{About the authors}

Kenta Suzuki obtained his B.Sc. and M.Sc. degrees from Tokyo University of Science (Japan). He is currently a Ph.D. course graduate student in Professor Soai's group.

Takashi Tsutsumi received his B.Sc. and M.Sc. degrees with Professor Soai and joined a chemical company in 2007.

Yukari Matsumura obtained her B.Sc. and M.Sc. degrees under the supervision of Professor Soai. She joined a chemical company in 2009.

Kenso Soai graduated from University of Tokyo (Japan) (B.Sc.) and obtained his Ph.D. degree (1979) with Professor T. Mukai yama. He was a fellow of the Japan Society for the Promotion of Science (JSPS). He joined the group of Professor E. L. Eliel

\section{REFERENCES}

(1) B. Barabás, L. Caglioti, K. Micskei, C. Zucchi, G. Pályi Orig. Life Evol. Biosph. 2008, 38, 317.

(2) M. M. Green, J.-W. Park, T. Sato, A. Teramoto, S. Lifson, R. L. B. Selinger, J. V. Selinger Angew. Chem. Int. Ed. 1999, 38, 3138.

(3) K. Soai, T. Shibata, H. Morioka, K. Choji Nature 1995. 378, 767.

(4) T. Kawasaki, H. Tanaka, T. Tsutsumi, T. Kasahara, I. Sato, K. Soai J. Am. Chem. Soc. 2006, 128, 6032.

Tsuneomi Kawasaki studied chemistry at the University of Tokyo and received his B.Sc. (1999) and Ph.D. (2004) degrees under the supervision of Professor Takeshi Kitahara. As a Research Associate, he moved to the Department of Applied Chemistry, Tokyo University of Science in the group of Professor Soai in 2004 where he currently is a Junior Assistant Professor. He received the Nissan Chemical Industry Award in Synthetic Organic Chemistry, Japan in 2005, the Royal Society of Chemistry: Organic \& Biomolecular Chemistry Poster Award in Chirality at the Nanoscale 2007 and the Lectureship Award of Young Generation Special Forum from the Chemical Society of Japan in 2009. 


\section{Thieme-Chemistry Journals Editorial Board Meetings 2009}

The 2009 Editorial Boards Meeting of the Thieme Chemistry journals SYNLETT, SYNTHESIS and SYNFACTS, including the supplement SYNFORM, was held on June $5^{\text {th }}$ and $6^{\text {th }}$ in the city of Granada (Spain). The Editorial Boards of the three journals and the staff of the Thieme Chemistry editorial office met at the Alhambra Palace Hotel. A manuscript submission system and initiatives to further increase the quality of the journals were among the most relevant issues which were discussed in a friendly and relaxed atmosphere.

The $40^{\text {th }}$ anniversary of SYNTHESIS and the $20^{\text {th }}$ anniversary of SYNLETT were also duly celebrated (see picture on the right), first with a toast to the two Editors-in-chief, Professor Dieter Enders and Professor K. Peter C. Vollhardt, respectively, followed by a general toast involving all of the Editorial Board members and accompanying persons. Among the main attractions of the night was the performance of the well-known folk song "La Cucaracha", brilliantly directed by Professor Erick M. Carreira, one of the SYNTHESIS Editors.
The program included a guided tour of the Alhambra (where the group picture was taken), the citadel-palace and fortress on a hill overlooking Granada. The Alhambra hosts royal residential quarters, court complexes flanked by official chambers, a mosque and beautiful gardens, which was

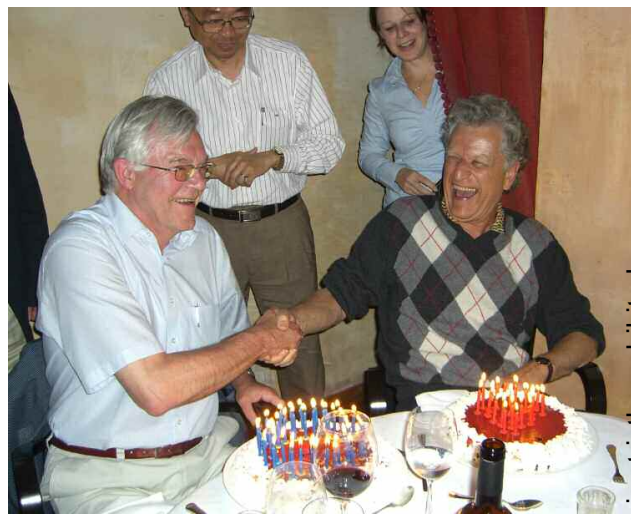
started in the thirteenth century by Ibn al-Ahmar, founder of the Nasrid dynasty, and was continued by his successors in the fourteenth century.

The appointment for the next Editorial Board Meeting is in 2010 in Florence (Italy).

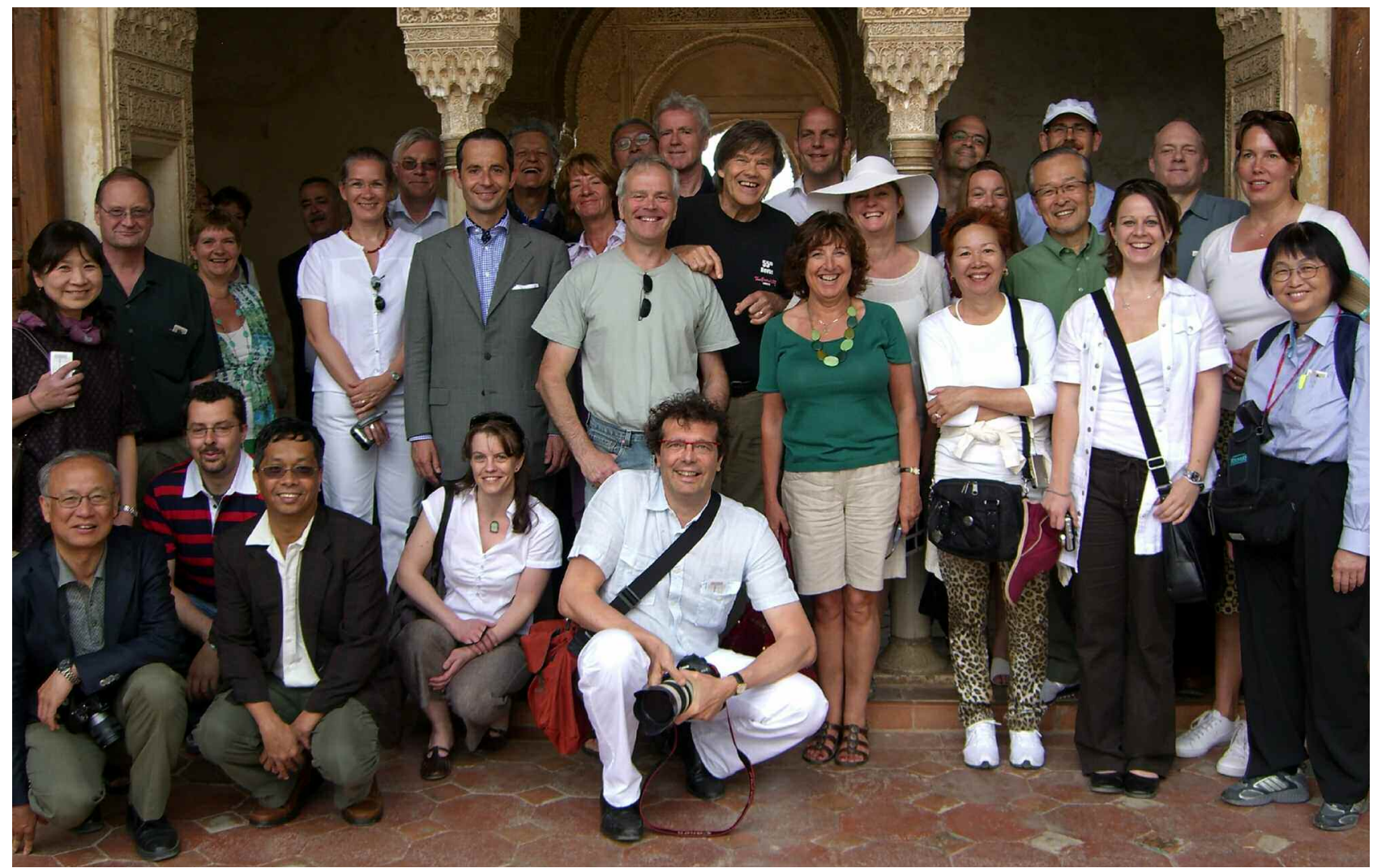


Matteo Zanda, C.N.R. - Istituto di Chimica del Riconoscimento Molecolare Via Mancinelli, 7, 20131 Milano, Italy

Synform@chem.polimi.it

Fax: +390223993080

\section{Editorial Office}

Managing Editor: Susanne Haak,

susanne.haak@thieme.de, phone: +49 7118931786

Scientific Editor: Selena Boothroyd,

selena.boothroyd@thieme.de

Assistant Scientific Editor: Stefanie Baumann,

stefanie.baumann@thieme.de, phone: +49711 8931776

Senior Production Editor: Thomas Loop,

thomas.loop@thieme.de, phone: +497118931778

Production Editor: Helene Deufel,

helene.deufel@thieme.de, phone: +49 7118931929

Production Assistant: Thorsten Schön,

thorsten.schoen@thieme.de, phone: +497118931781

Editorial Assistant: Sabine Heller,

sabine.heller@thieme.de, phone: +49 7118931744

Marketing: Thomas Krimmer,

thomas.krimmer@thieme.de, phone: +497118931772

Postal Address: SYNTHESIS/SYNLETT/SYNFACTS, Editorial Office,

Georg Thieme Verlag KG, Rüdigerstraße 14, 70469 Stuttgart, Germany, phone: +49 7118931744 , fax: +49 7118931777

Homepage: www.thieme-chemistry.com

Publication Information

SYNFORM will be published 9 times in 2009 by Georg Thieme Verlag KG, Rüdigerstraße 14, 70469 Stuttgart, Germany, and is an additional online service for SYNTHESIS, SYNLETT and SYNFACTS

Palladium-Catalyzed Allylic Amination Using Aqueous Ammonia for the Synthesis of Primary Amines

(Focus on an article from the current literature)

Publication Policy

Product names which are in fact registered trademarks may not have been specifically designated as such in every case. Thus, in those cases where a product has been referred to by its registered trademark it cannot be concluded that the name used is public domain. The same applies as regards patents or registered designs.

Ordering Information for Print Subscriptions to SYNTHESIS, SYNLETT and SYNFACTS

Americas: Thieme New York, 333 Seventh Avenue, New York, NY 10001 , USA. To order: customerservice@ thieme.com or use the Web site facilities at www.thieme.com, phone: +12127600888

Order toll-free within the USA: +18007823488 Fax: +1 2129471112

Airfreight and mailing in the USA by Publications Expediters Inc., 200 Meacham Ave., Elmont NY 11003. Periodicals postage paid at Jamaica NY 11431.

All other countries: Thieme Publishers, Rüdigerstraße 14

70469 Stuttgart, Germany. To order: customerservice@thieme.de or use the Web site facilities at www.thieme.com.

For further inquries please contact Mrs. Birgid Härtel

Phone: +49 7118931 421; Fax: +49711 8931410

SYNTHESIS

Special Issue on "Total Synthesis" in issue 17/2009

\section{SYNLETT}

Account on: Developing Continuous-Flow Microreactors as Tools for Synthetic Chemists

(by P. H. Seeberger)

\section{SYNFACTS}

Synfact of the Month in category "Synthesis of Heterocycles": Synthesis of 5-Alkoxy Pyrimidines via Enamides

\begin{tabular}{l} 
CONTACT \\
Matteo Zanda, \\
C.N.R. - Istituto di Chimica del Riconoscimento Molecolare, \\
Via Mancinelli, 7, 20131 Milano, Italy, \\
e-mail: Synform@chem.polimi.it, fax: +39 0223993080 \\
\hline
\end{tabular}

\section{Online Access via Thieme-connect}

The online versions of SYNFORM as well SYNTHESIS, SYNLETT and SYNFACTS are available through Thieme-connect (www.thieme-

connect.com/ejournals) where you may also register for free trial accounts. For information on multi-site licenses and pricing for corporate customers as well as backfiles please contact our regional offices:

Americas: esales@thieme.com,phone: +1 2125844695

All other countries: eproducts@thieme.de, phone: +49 7118931407

Manuscript Submission to SYNTHESIS and SYNLETT

Please consult the Instructions for Authors before compiling a new manuscript. The current version and the Word template for manuscript preparation are available for download at www.thieme-chemistry.com. Use of the Word template helps to speed up the refereeing and production process.

\section{Copyright}

This publication, including all individual contributions and illustrations published therein, is legally protected by copyright for the duration of the copyright period. Any use, exploitation or commercialization outside the narrow limits set by copyright legislation, without the publisher's consent, is illegal and liable to criminal prosecution. This applies translating, copying and reproduction in printed or electronic media forms (databases, online network systems, Internet, broadcasting, telecasting, CD-ROM, hard disk storage, microcopy edition, photomechanical and other reproduction methods) as well as making the material accessible to users of such media (e.g., as online or offline backfiles).

\section{Copyright Permission for Users in the USA}

Authorization to photocopy items for internal or personal use, or the internal or personal use of specific clients, is granted by Georg Thieme Verlag KG Stuttgart · New York for libraries and other users registered with the Copyright Clearance Center (CCC) Transactional Reporting Service, provided that the base fee of US\$ 25.00 per copy of each article is paid directly to CCC, 22 Rosewood Drive, Danvers, MA 01923, USA, 0341-0501/02. 